\title{
APOCRINE CARCINOMA OF BREAST- A RARE CASE REPORT
}

\author{
Utpala Uday', Mallikarjuna N. Managi ${ }^{2}$
}

1 Junior Resident, Department of General Surgery, Bangalore Medical College and Research Institute, Bengaluru, Karnataka. ${ }_{2}^{2}$ Assistant Professor, Department of General Surgery, Bangalore Medical College and Research Institute, Bengaluru, Karnataka.

HOW TO CITE THIS ARTICLE: Uday U, Managi MN. Apocrine carcinoma of breast- a rare case report. J. Evolution Med. Dent. Sci. 2017;6(72):5177-5178, DOI: 10.14260/Jemds/2017/1124

\section{BACKGROUND}

Apocrine carcinoma is a rare variant of breast carcinoma, accounting for $\sim 0.4 \%$ of invasive breast tumours.1,2 The clinical profile of apocrine carcinoma is indistinguishable from infiltrative ductal carcinoma- no special type (IDC-NST). It is characterised by the distinct microscopic appearance of abundant eosinophilic granular cytoplasm and multiple prominent nucleoli ${ }^{3,4}$; and oestrogen/progesterone negative, androgen positive (ER-/PR-/AR+) receptor profile. ${ }^{5}$

\section{PRESENTATION OF CASE}

A 58-year-old female initially presented to the surgery department with the complaint of lump in the left breast since last 6 months, which had been gradually increasing in size. She denied any complaints of swelling in the axilla. On local examination, a solitary hard mass of $8 \times 7 \mathrm{~cm}$ was noted in the upper outer and inner quadrant of left breast with concomitant nipple retraction. There was no evidence of axillary lymphadenopathy.

\section{PATHOLOGICAL DISCUSSION}

On evaluation, mammography showed an ill-defined irregular opacity graded as BIRADS VI and axillary sonography revealed few subcentimetric lymph nodes, largest measuring $10 \times 8 \mathrm{~cm}$. FNAC was suggestive of carcinoma of breast and showed high cellularity with pleomorphic cells showing high $\mathrm{N}: \mathrm{C}$ ratio. The patient underwent 4 cycles of Docetaxel-based neoadjuvant chemotherapy with only minimal-to-modest response, followed by modified radical mastectomy. The histopathology showed presence of $4.5 \times 4 \times 4 \mathrm{~cm}$ lesion with microscopic presence of oval-polygonal cells with abundant eosinophilic cytoplasm and pleomorphic nuclei. Metastasis was present in 8 regional lymph nodes. The patient was triple receptor negative (ER-/PR-/HER-2/neu-) and androgen receptor positive. She completed the course of chemotherapy and local radiotherapy and was disease free at 1 year of followup.

Financial or Other, Competing Interest: None

Submission 31-07-2017, Peer Review 23-08-2017,

Acceptance 30-08-2017, Published 07-09-2017.

Corresponding Author:

Dr. Utpala Uday,

House No. 25,

Reliance Greens,

Motikhavdi,

Jamnagar-361142,

Gujarat.

E-mail: 4u.utpala@gmail.com

DOI: $10.14260 /$ jemds/2017/1124

\section{(c) () () $\ominus$}

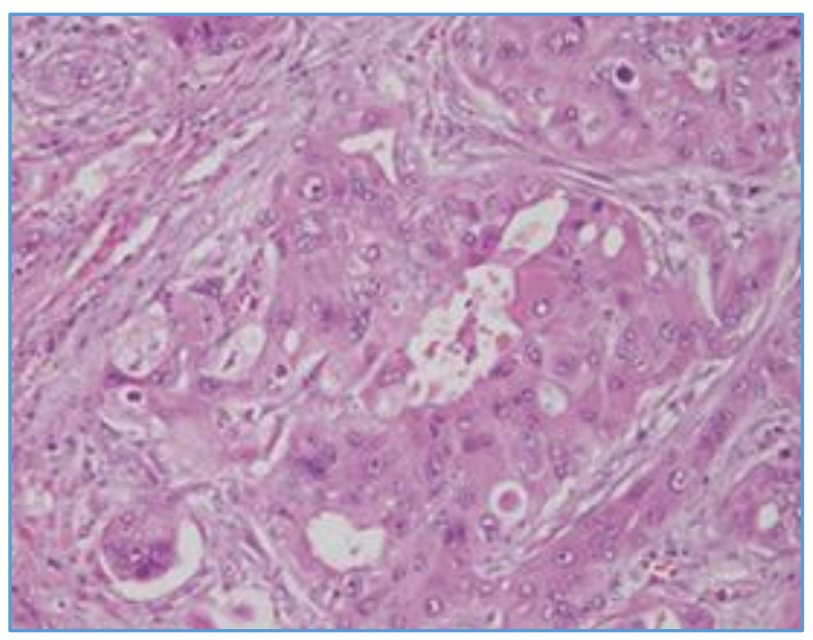

Figure 1. Photomicrograph showing Large Nuclei with Eosinophilic Cytoplasm and Prominent Nucleoli consistent with Apocrine Differentiation

\section{DISCUSSION}

Invasive carcinoma of the breast is a heterogeneous disease with more than 20 different variants described based on morphologic, molecular and clinical terms. ${ }^{6}$ The reported incidence of invasive apocrine carcinoma is between 0.3 and $4 \% .^{7}$ The mean age at presentation is in the $6^{\text {th }}$ and $7^{\text {th }}$ decade ${ }^{1,8,9}$ with only female cases described in literature.

The significant variations in incidence noted may be attributed to the lack of consistent and accepted diagnostic criteria. In 2005 Japaze et $\mathrm{al}^{8}$ proposed the morphologic criteria for the diagnosis of apocrine carcinoma, which is the current standard. It consists of five mandatory patterns as-

1. Apocrine features consisting of $75 \%$ of cells.

2. Large cells with eosinophilic granular cytoplasm.

3. Nucleus to cytoplasmic ratio of 1:2 or more.

4. Nucleus large, round and vesicular may be pleomorphic.

5. Sharply defined borders.

Minor and non-mandatory criteria include prominent nucleoli in $>50 \%$ of fields and apical cytoplasmic snouts into luminal spaces. $0^{\prime}$ Malley et al ${ }^{10}$ defined invasive apocrine carcinoma as the presence of malignant apocrine cells in more than $90 \%$ of the tumour population.

Vranic et al ${ }^{11}$ concurred that these are molecularly diverse cancers. They defined pure apocrine cancer (PIAC) by its characteristic profile of oestrogen and progesterone negativity and androgen receptor positivity (ER-/PR-/AR+). On the other hand, apocrine-like tumours do not have the characteristic steroid receptor expression profile and are more likely to have a luminal phenotype. Reported incidences of HER-2 overexpression vary from 33\% to 54\%.1,9,11 Gross cystic disease fluid protein 15 (GCDFP-15) has been identified as a marker for apocrine differentiation in breast; however, its expression appears to be decreased in advanced apocrine carcinomas. ${ }^{12}$ 
Clinical and radiological presentation of apocrine carcinoma is no different from that of invasive ductal carcinomas (NST). ${ }^{10,12}$ The mean tumour size is greater, 2 $\mathrm{cm} .1,9$ It tends to be unilateral, but multifocality multicentricity is seen frequently. ${ }^{13}$ Apocrine carcinoma is associated with a lower frequency of axillary nodal involvement and less lymphovascular involvement.1,9 Our case, probably owing to the late presentation showed both these features.

Nagao et al $^{14}$ in their study have indicated a poor response to chemotherapy in patients with apocrine carcinomas, although HER-2/neu enriched carcinomas tend to have the highest rate of complete response to neoadjuvant chemotherapy. However, according to $\mathrm{Tsutsumi}^{5}$ there appears to be a potential unique response to androgen (fluoxymesterone) administration as a part of treatment which is under investigation.

The available prognostic data for apocrine carcinoma is contradictory with most studies showing no difference from stage matched invasive breast carcinoma- NST. ${ }^{8}$ However, some recent studies have shown significantly better prognosis of pure apocrine carcinoma (PIAC) with overall sixyear survival of $72 \%$ as against $52 \%$ for IDC-NST. ${ }^{8}$ PIAC may be regarded as an independent clinico-pathological prognostic factor in early breast cancer.

\section{CONCLUSION}

Invasive apocrine carcinoma of breast is a distinct, albeit rare clinico-pathological entity. Its characteristic steroid receptor expression profile might be a route for targeted therapy as well as a guide for management and prognosis. It thus justifies identifying apocrine carcinoma as a unit different from the common invasive ductal carcinoma.

\section{FINAL DIAGNOSIS}

Breast carcinoma- apocrine type.

\section{REFERENCES}

[1] Matsuo K, Fukutomi T, Hasegawa T, et al. Histological and immunohistochemical analysis of apocrine breast carcinoma. Breast Cancer 2002;9(1):43-9.

[2] Mossler JA, Barton TK, Brinkhous AD, et al. Apocrine differentiation in human mammary carcinoma. Cancer 1980;46(11):2463-71.
[3] Yerushalmi R, Hayes MM, Gelmon KA. Breast carcinoma - rare types: review of the literature. Annals of Oncology 2009;20(11):1763-70.

[4] Durham JR, Fechner RE. The histologic spectrum of apocrine lesions of the breast. The American Journal of Clinical Pathology 2000;113(5 Suppl 1):S3-S18.

[5] Tsutsumi Y. Apocrine carcinoma as triple-negative breast cancer: novel definition of apocrine-type carcinoma as estrogen/ progesterone receptornegative and androgen receptor positive invasive ductal carcinoma. Japanese Journal of Clinical Oncology 2012;42(5):375-86.

[6] Weigelt B, Geyer FC, Reis-Filho JS. Histological types of breast cancer: how special are they? Mol Oncol 2010;4(3):192-208.

[7] Vranic S, Schmitt F, Sapino A, et al. Apocrine carcinoma of the breast: a comprehensive review. Histol Histopathol 2013;28(11):1393-409.

[8] Japaze H, Emina J, Diaz C, et al. 'Pure' invasive apocrine carcinoma of the breast: a new clinicopathological entity? Breast 2005;14(1):3-10.

[9] Tanaka K, Imoto S, Wada N, et al. Invasive apocrine carcinoma of the breast: clinicopathologic features of 57 patients. Breast J 2008;14(2):164-8.

[10] O'Malley FP, Pinder SE, Mulligan AM. Breast Pathology. $2^{\text {nd }}$ edn. Saunders Elsevier 2011.

[11] Vranic S, Tawfik 0, Palazzo J, et al. EGFR and HER$2 /$ neu expression in invasive apocrine carcinoma of the breast. Mod Pathol 2010;23(5):644-53.

[12] Lakhani SR, Ellis IO, Schnitt SJ, et al. WHO classification of tumours of the breast. Lyon, France: IARC 2012.

[13] Unal E, Firat A, Gunes P, et al. Apocrine carcinoma of the breast: clinical, radiologic and pathologic correlation. Breast J 2007;13(6):617-8.

[14] Nagao T, Kinoshita T, Hojo T, et al. The differences in the histological types of breast cancer and the response to neoadjuvant chemotherapy: the relationship between the outcome and the clinicopathological characteristics. Breast 2012;21(3): 289-95. 